\title{
Habitat suitability and impacts of climate change on the distribution of wintering population of Asian Houbara Bustard Chlamydotis macqueenii in Iran
}

\author{
MASOUD YOUSEFI, MOHSEN AHMADI, ELHAM NOURANI, ALI REZAEI, \\ ANOOSHE KAFASH, ALI KHANI, MOHAMMAD EBRAHIM SEHHATISABET, \\ MOHAMAD ALI ADIBI, FAHIMEH GOUDARZI and MOHAMMAD KABOLI
}

\begin{abstract}
Summary
We developed a habitat suitability model for wintering populations of the Asian Houbara Bustard Chlamydotis macqueenii in Iran and determined environmental variables affecting its occurrence. Our results indicate that various patches in central, western and eastern Iran provide the most suitable habitats for the Houbara. Annual precipitation, slope and distance to croplands were the most important variables for predicting Houbara occurrence. We also determined the effects future climate changes on the distribution of the Houbara in Iran. Results showed that suitable habitats for the wintering Houbara will increase in Iran, but will also considerably shift under future climatic conditions. The distribution maps that we present for the present and future climatic conditions can have important implications for the conservation and management of Houbara populations in Iran.
\end{abstract}

\section{Introduction}

The Asian Houbara Bustard Chlamydotis macqueenii (hereafter Houbara) is a globally threatened (IUCN status 'Vulnerable') bird inhabiting desert and semi-desert areas from the Nile River in Egypt to the Gobi desert in Mongolia (Gao et al. 2009, Combreau et al. 2011). Listed on Annex I of CITES species Annex II of CMS (Convention on Migratory Species), the Houbara is declining in much of its range and many of its breeding populations are in danger of extinction (Combreau et al. 2005). It is faced by threats such as hunting and trapping by falconers and human-induced habitat degradation in much of its range (Goriup 1997, Yang et al. 2003, Combreau et al. 2005, Mansouri 2006, Gao et al. 2009). The main driver of population declines of the species is hunting throughout its wintering range (Tourenq et al. 2005, Riou et al. 2011, BirdLife International 2014). The CMS Asian Houbara Agreement, drafted in 2005, urges all range countries to take necessary measures to prevent the extinction of any population of the Houbara and maintain a favourable status for the species throughout its range (Combreau et al. 2005).

Species Distribution Models (SDMs) are useful tools for conservation and management of species, by depicting patterns of distribution through identifying the effects of natural and humanrelated variables (Phillips and Dudík 2008, Cayuela et al. 2009). These models are especially useful for identifying potential occurrence localities of poorly documented species, determining the most important factors that limit their distribution, and evaluating the effects of climate and land use changes on their distribution (Phillips et al. 2006, Cayuela et al. 2009, Liu et al. 2011, López-Jamar et al. 2011, Osborne and Seddon 2012, Velásquez-Tibatá et al. 2012). 
To facilitate conservation of the Houbara, various studies have focused on habitat requirements and distribution in the range countries (Combreau and Smith 1997 Heezik and Seddon 1999, Yang et al. 2003, Carrascal et al. 2008, Aghainajafi-Zadeh et al. 2010). Habitat suitability of the Houbara has most commonly been associated with flatness of terrain (Carrascal et al. 2008), sparse vegetation (Combreau and Smith 1997, Mian 2003, Yang et al. 2003, Aghainajafi-Zadeh et al. 2010) and low human disturbance (Mansoori and Kiabi 2003, Le Cuziat et al. 2005a, 2005b).

A significant portion of resident and wintering populations of Houbara are dispersed over a vast range in deserts and semi-arid habitats of the central Iranian plateau (Scott et al. 1975, Kaboli et al. 2012). Considerable research has been done in Iran regarding the status (Mansoori and Kiabi 2003, Mansouri 2006), feeding biology (Aghainajafi-Zadeh et al. 2011), habitat selection (Aghainajafi-Zadeh et al. 2010), and captive breeding (Heydari et al. 2010) of this species. However, studies on the distribution of the Houbara and eco-geographic variables limiting its distribution have been scarce (Mansoori and Kiabi 2003), hampering effective conservation planning for this species.

We developed a maximum entropy (Maxent) presence-only distribution model (Phillips et al. 2006) for the wintering populations of the Houbara in Iran to determine the influence of variables on the species' distribution. We expected that, like other birds of arid steppe, topographic features (Kaboli et al. 2006), especially slope (Carrascal et al. 2008), would be the major limiting factors in Houbara distribution. We also expected that low vegetation cover and precipitation would be important in shaping Houbara distribution because they are significant aspects of arid steppe. Consequently, we hypothesised that apart from the Alborz and Zagros Mountains in the north and the northwest, suitable habitats would be found in much of the country, especially in the central and eastern parts of the Iranian Plateau.

We also assessed the effects of future climate changes on the distribution of the Houbara in Iran. Projections of the future climatic conditions indicate that the amount and pattern of precipitation will be altered with a global change in temperature, putting a wide range of species at risk (Şekercioğlu et al. 2012, Avalos and Hernández 2015). We therefore speculate that this species will be severely affected as climate change progresses.

\section{Materials and methods}

\section{Species distribution data}

Data on species occurrence can be obtained from various sources such as museums, atlases or survey studies on target species (Moura et al. 2012). These data, together with environmental data, can be used to build SDMs that allow for determining areas with suitable habitats and potential distribution (Phillips et al. 2006, Moura et al. 2012). To do so, we used Maxent, a robust modelling approach that effectively takes into account various data sources (Phillips and Dudík 2008). Our data on occurrence of the Houbara (see online supplementary material) were collected through fieldwork in October-February 2010-2014. The coverage of presence points is not limited to roadside or other easily accessible areas, but rather resulted from observations made by ornithologists of Department of Environment of Iran, who regularly monitor bird fauna in arid landscapes of Iran.

\section{Explanatory variables}

We used 12 macro-scale environmental variables, which can be placed into four categories, including land cover, topography, anthropogenic, and bioclimatic variables (Table I). We used land cover as a means of incorporating important predictors such as habitat type, vegetation structure, and food availability in our modelling (Seoane et al. 2004, Aghainajafi-Zadeh et al. 2011). Land cover types included croplands, rangelands (steppe with herbaceous vegetation and scattered scrub), and shrublands (scrub and woodlands), important variables that influence Houbara 
Table 1. Environmental variables used in developing a distribution model for the Houbara in Iran.

\begin{tabular}{|c|c|c|c|}
\hline Predictive variable & Description & Source & Unit \\
\hline \multirow[t]{2}{*}{ Topographic } & Altitude: Elevation above sea level & Jarvis et al. 2008 & $\mathrm{~m}$ \\
\hline & Slope: steepness & Jarvis et al. 2008 & $\%$ \\
\hline \multirow[t]{2}{*}{ Anthropogenic } & Roads: Distance to roads & IFRWO, 2010 & Degrees \\
\hline & $\begin{array}{l}\text { Human settlements: Distance to urban } \\
\text { and rural areas }\end{array}$ & IFRWO, 2010 & Degrees \\
\hline \multirow[t]{2}{*}{ Land cover } & Croplands: Distance to nearest agricultural patch & IFRWO, 2010 & Degrees \\
\hline & $\begin{array}{l}\text { Shrub-lands: Distance to the nearest } \\
\text { patch covered by scrubs/shrubs } \\
\text { Rangeland: Distance to the nearest } \\
\text { patch covered by grass or grassland with } \\
\text { scattered crops or woody vegetation }\end{array}$ & IFRWO, 2010 & Degrees \\
\hline \multirow[t]{5}{*}{ Bioclimatic } & Annual precipitation & Hijmans et al. 2005 & $\mathrm{~mm}$ \\
\hline & Temperature seasonality (standard deviation * 100 & Hijmans et al. 2005 & ${ }^{\circ} \mathrm{C}$ \\
\hline & $\begin{array}{l}\text { Mean diurnal range [Mean of monthly } \\
\text { (max temp - min temp)] }\end{array}$ & Hijmans et al. 2005 & ${ }^{\circ} \mathrm{C}$ \\
\hline & Maximum temperature of warmest month & Hijmans et al. 2005 & ${ }^{\circ} \mathrm{C}$ \\
\hline & Isothermality & Hijmans et al. 2005 & Dimensionless \\
\hline
\end{tabular}

distribution (Mansoori and Kiabi 2003, Aghainajafi-Zadeh et al. 2010, 2012, Carrascal et al. 2012, Asadalla et al. 2015). Land cover data were obtained from the Iranian Forests, Range and Watershed Management Organization (IFRWO) National Land Cover map. This data was derived from $30 \mathrm{~m}$ Landsat Enhanced Thematic Mapper Plus (ETM+) imagery for the conterminous Iran in the year 2010 .

Distance to human settlements (urban and rural areas) and distance to roads were included in the model because it is believed that these anthropogenic variables influence Houbara distribution (Mansoori and Kiabi 2003, Aghainajafi-Zadeh et al. 2011). To provide continuity for the extracted categories (Franklin 2009), we calculated the Euclidian distance to nearest patch of each cover type by running the ArcMap Spatial Analyst tools.

Climatic variables were obtained from the WorldClim database (Hijmans et al. 2004). This database consists of 19 climatic variables for all countries, interpolated based on data derived from climatic stations. Using the Shuttle Radar Topography Mission (SRTM) elevation model, two topographic explanatory variables, altitude and slope, were compiled as the most important variables affecting the distribution of physiographic roughness. Because of the multicollinearity between climatic variables, we only used those that were uncorrelated (Pearson's $r \leq 0.70$ ) (Asuero et al. 2006). We then checked for correlation between all 12 environmental variables and found no correlation between them. In order to determine pairwise correlation, we used ENM tools (Warren et al. 2010). Regarding the grid size of climatic variables at approximately $1-\mathrm{km}^{2}$ precision $(30 \times$ 30 arcseconds), all other environmental variables were prepared with the same grid size.

\section{Data analysis}

Maxent can be used to estimate species distribution by finding the probability distribution with maximum entropy (i.e. closest to uniform) for the study area under a specified set of environmental constraints (Phillips et al. 2006). Comparative studies show that Maxent outperforms other accepted quantitative methods for ecological modelling (Hernandez et al. 2006, Gastón and García-Viñas 2011).

Maxent was run with maximum iterations of 500, convergence threshold of 0.0001 and 10000 background points. We randomly partitioned occurrence records of the species into a training set with $80 \%$ of the records and the test set with $20 \%$ of the records. The performance of the model was assessed using the Area Under the Curve (AUC) metric of Receiving Operator Characteristic 
(ROC) curve (Phillips et al. 2006). Maxent plots all sensitivity values (true positives) against I-specificity (false positives) values and calculates the AUC to provide a threshold-independent metric of overall accuracy, ranging between 0.5 (no predictive ability or randomness) and 1.0 (perfect predictive ability). Models with AUC $>0.75$ are considered adequate and $>0.90$ are considered excellent (Swets 1988, Elith 2000).

We also obtained alternative estimates of variable importance for our Maxent models by conducting a jackknife analysis. Jackknife systematically recomputed the AUC for each model leaving out one environmental variable at a time. This provided the ability to assess the extent to which each variable contributed to the model individually and how model performance was affected by the omission of each variable (Phillips et al. 2006, Elith et al. 2011).

\section{Assessing the effects of future climate changes}

In order to assess the impact of climatic change on the Houbara, we developed a climate-only SDM using annual precipitation, temperature seasonality, mean diurnal range, maximum temperature of warmest month and isothermality, downloaded from WorldClim dataset. We then projected the model to future climate conditions for the year 2070 (average for 2061-2080) using Maxent software (Phillips et al. 2006).

We used the output from the general circulation model $\mathrm{CCSM}_{4}$ from the Intergovernmental Panel on Climate Change (IPCC) 4th Assessment Report (https://www.ipcc.ch/publications_and_ data/publications_ipcc_fourth_assessment_report_synthesis_report.htm). Based on different inputs of greenhouse gas emission drivers (i.e. population and economic growth, and technological choices), land use changes, environmental policy options, and adaptation processes (Solomon et al. 2007), the IPCC recommended four representative concentration pathways (RCPs) that became a part of the IPCC Fifth Assessment Report finalised in 2014 (https://www.ipcc.ch/report/ar5/). Each pathway is defined by a radiative forcing value, which describes the change in the amount of energy entering the atmosphere and the quantity reflected back, and is expressed in watts per square meter of surface $(\mathrm{W} / \mathrm{m} 2)$. We considered RCPs 2.6 and 8.5, which described a possible future range of energy state for the earth on the basis of different trends in climate change drivers. We then calculated and compared the climatically suitable areas for the species in the present climatic conditions and future climactic change scenarios using ArcGIS 9.3 (ESRI 2009).

We used 0.35 (1o percentile training presence logistic threshold (Young et al. 2011) as threshold value to classify Houbara continuous suitability model to suitable/unsuitable classes, so areas with less than 0.35 suitability values in Houbara distribution model were considered as unsuitable habitats. Areas with suitability of higher than 0.35 were categorised into two equal classes, $0.35-0.675$ moderate suitability and $0.675^{-1}$ as high suitability. We used a similar approach and classified climate-only model with a threshold value of 0.3 . Areas with higher suitability than 0.3 were categorised into two equal classes, $0.3-0.65$ moderate suitability and $0.65-1$ as high suitability.

\section{Results}

Habitat suitability modelling indicated that a vast area within the Central Iranian Plateau, excluding the deserts of central Iran, has moderate suitability for wintering population of the Houbara. Additionally, the plains of the western Zagros Mountains in the south-westernmost regions of the country and some plains in the north and north-east of the country, north of Alborz Mountains and Kopet Dagh have moderate suitability. Our model also indicates other dispersed patches of suitable habitats throughout the country (Fig. I).

\section{Variable contributions}

Analyses of relative predictive power of environmental variables showed that annual precipitation, slope and distance to cropland were the most important in predicting the distribution of the Houbara, 


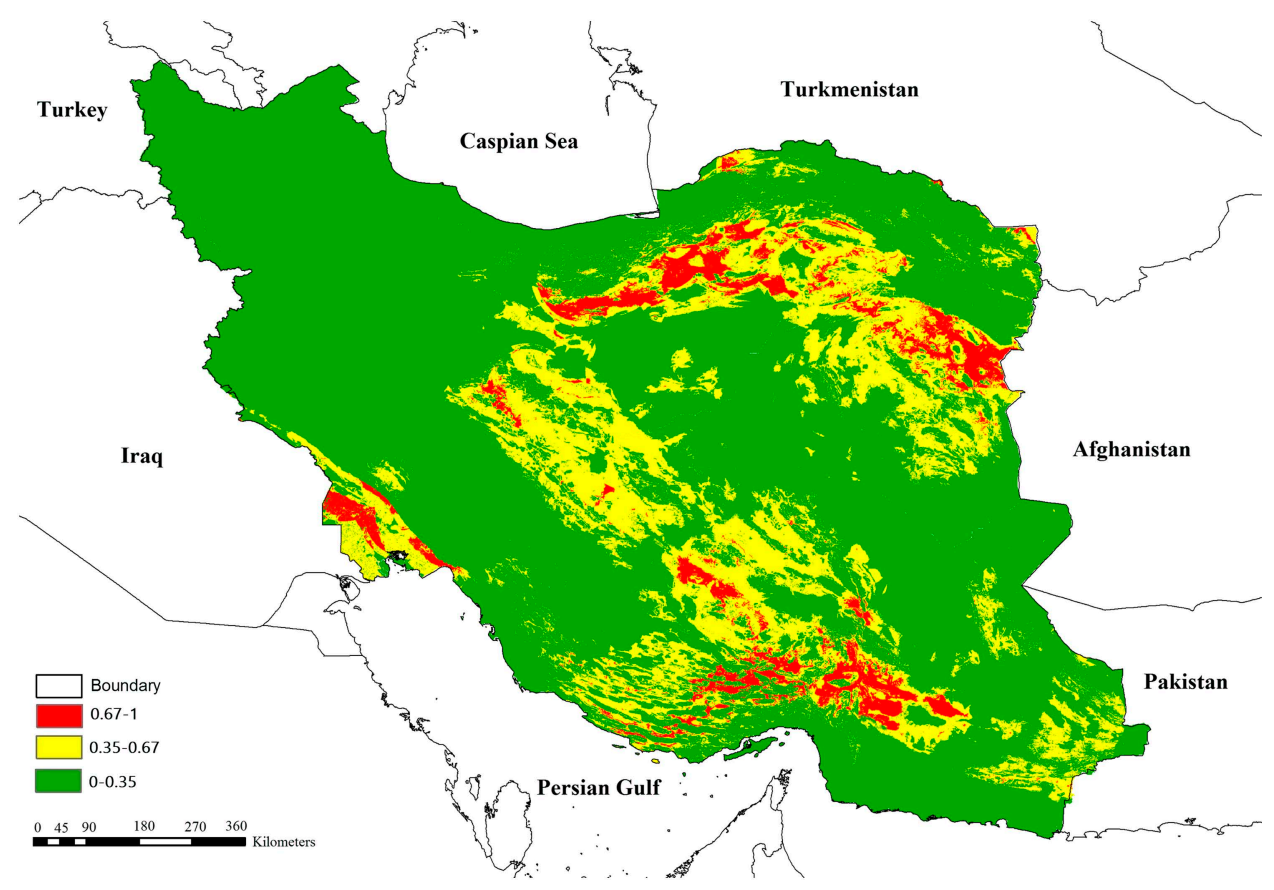

Figure 1. Habitat suitability map of the wintering populations of Houbara in Iran. The distribution of protected areas indicates low representation of suitable habitats of the Houbara within the ICN.

with $34.6 \%, 22.8 \%$, and $19.5 \%$ contributions respectively (Table 2 ), all with an overall negative effect (Figure 2). The results of analysis of variable contribution using a jackknife procedure also indicated that the environmental variable with highest gain when used in isolation is annual precipitation, which therefore appears to have the most useful information by itself. Moreover, model gain decreases the most when this variable is omitted, indicating that it has the most information that is not present in the other variables.

We found that although an increase in annual precipitation results in higher habitat suitability due to better vegetation conditions, this positive trend is only observed when annual precipitation reaches about $170 \mathrm{~mm}$. Areas receiving higher annual precipitation are outside the semi-arid

Table 2. Relative contribution of each environmental variable in Houbara distribution model. The results of the jackknife test of variable importance. "Without variable"- each variable is excluded in turn and a model created with the remaining variables; "With only variable"- model constructed using only one variable.

\begin{tabular}{llll}
\hline Variable & Percent contribution & Without variable & With only variable \\
\hline Annual Precipitation & 36.4 & 0.389 & 0.198 \\
Slope & 22.8 & 0.472 & 0.159 \\
Distance to croplands & 19.5 & 0.443 & 0.037 \\
Altitude & 5.2 & 0.495 & 0.043 \\
Distance to shrub-lands & 4.7 & 0.489 & 0.034 \\
Distance to human settlements & 4.6 & 0.494 & 0.009 \\
Temperature seasonality & 2.4 & 0.507 & 0.001 \\
Distance to rangelands & 1.8 & 0.516 & 0.033 \\
Maximum temperature of warmest month & 1.1 & 0.528 & 0.061 \\
Distance to roads & 0.9 & 0.523 & 0.008 \\
Isothermality & 0.7 & 0.526 & 0.017 \\
\hline
\end{tabular}



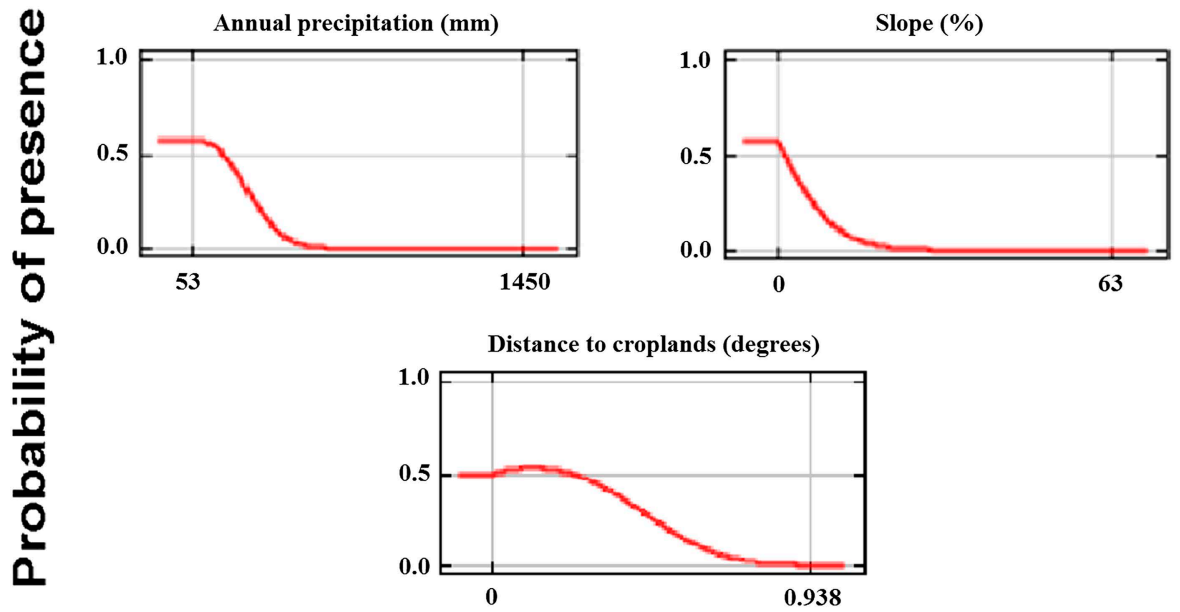

Figure 2. Response curves showing how the presence of the Houbara in Iran is affected by the most important variables.

regions in which the Houbara occurs and therefore are associated with unsuitability. Such regions, mostly located in the Alborz and Zagros Mountains, show different habitat types due to high precipitation and slope from those tolerated by the Houbara. A similar pattern is shown by the response curves for slope. Increasing slope (>10\%) reduces the suitability of habitat for the Houbara, which is a steppe bird confined to flat plains. Moreover, the higher suitability of habitats in the vicinity of cropland indicates that the birds are so dependent on the existence of cropland that habitats more than $6 \mathrm{~km}$ away lose their suitability for the Houbara (Figure 2).

The overall predictive ability of the models (General model: AUC $=0.847$ for training and 0.843 for test data, climate-only model CCSM2.6: $\mathrm{AUC}=0.872$ for training and 0.822 for test data, climate-only model CCSM8.5: AUC $=0.862$ for training and 0.816 for test data) showed high discriminatory capacity in determining suitable and unsuitable habitats.

\section{Houbara distribution under climate change}

Results of assessing the effects of climate changes on the distribution of the Houbara in Iran showed that suitable habitats would increase in the future (Table 3). However, projections also revealed considerable shifts in the geographic distribution of suitable habitats to currently unsuitable areas (Figure 3).

\section{Discussion}

The distribution map that we developed for the Houbara in Iran is in concordance with previous knowledge on the species' distribution (Mansoori and Kiabi 2003, Mansoori 2006). We found

Table 3. Percentage cover of climate-only models within the probability classes for the distribution of Houbara in Iran.

\begin{tabular}{lccc}
\hline Probability classes & Current & Future_2.6 & Future_8.5 \\
\hline $0-0.3$ & 59 & 57 & 51 \\
$0.3-0.65$ & 33 & 37 & 35 \\
$0.65-1$ & 8 & 6 & 14 \\
\hline
\end{tabular}



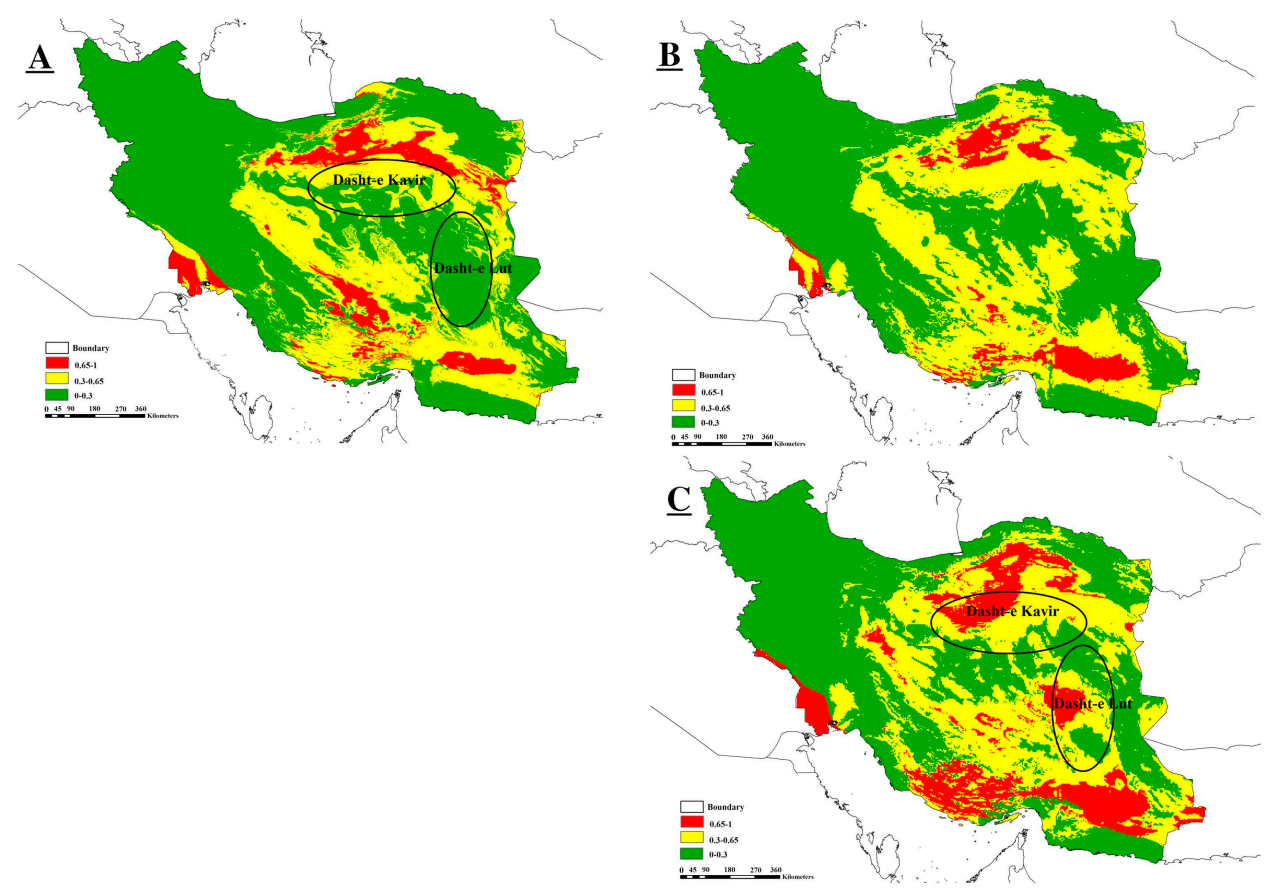

Figure 3. Models of habitat suitability for the species based on the present climatic data (A) and CCSM2.6 (B) and CCSM8.5 (C) for the future.

annual precipitation to be the most important predictor of Houbara presence, possibly due to its effect on vegetation conditions and productivity of the arid habitats occupied by this species (Mian 2003, Carrascal et al. 2008). Precipitation in desert and semi-desert areas of Iran varies from zero in Dasht-e Lut and Dasht-e Kavir in central Iran, to 160-170 mm at the edges of deserts and semi-deserts. With increasing precipitation, suitability increases for this species and reaches a maximum in areas that receive around $170 \mathrm{~mm}$ of annual precipitation. However, as precipitation exceeds this threshold, landscape type also changes, mostly becoming highly elevated and with steep slopes, which are not suitable for the Houbara.

Topography is another major predictor of regional distribution of avifauna in arid environments (Kaboli et al. 2006). Steppe birds occupy habitats with a level relief and structural simplicity (de Juana 2005). Although we initially expected topography, particularly slope, to be the most important variable, our results indicate that slope is the second most important limiting factor for the wintering population of the Houbara and that suitability is reduced in regions with slopes $>10 \%$. Consequently, major mountainous areas in the country fall into the range of unsuitable habitats in our model.

Previous studies on the wintering populations of the Houbara indicate that the birds regularly visit croplands to feed (Aghainajafi-Zadeh et al. 2010). Our results are in concordance with these findings, as vicinity to cropland was the next most important variable in determining habitat suitability for the Houbara. With an increase in habitat loss, farmlands provide the most similar habitats to the homogenous open terrain that steppe birds naturally occupy (de Juana 2005). Croplands and farmlands have therefore commonly been reported as an important habitat requirements of bustard species (Lane et al. 2001, Osborne et al. 2001, Gray et al. 2007, Suárez-Seoane et al. 2008). For instance, in landscapes comprising natural steppes interspersed with agricultural patches, Little Bustards Tetrax tetrax are likely to shift their habitats closer to agricultural land and use them in addition to, or in compensation for, the resources that the natural habitat provides (Wolff 2005). There is a downside to the attractiveness of croplands for the Houbara, however, since these 
human-dominated areas might become ecological traps (Battin 2004), leading the Houbara to high-risk areas where hunting is a threat.

We investigated the effect of human disturbance on habitat suitability of Houbara by including two related variables (distance to human settlements and distance to roads) in the models. However, these variables did not prove to be critical. This finding might seem inconsistent with the previous finding about vicinity to agricultural land and it might be argued that agriculture is a form of human disturbance. However, by considering the agricultural landscape in arid and semiarid areas of Iran, where such land uses are often located at considerable distances from villages and accessible by dirt roads, a distinction can be made between these variables.

Projecting the Houbara climate-only model to future climatic conditions showed an increase in the overall area of suitable habitat in Iran. However, considerable shifts in the geographic distribution of suitable habitats were also observed, which will mean that birds occupying different parts of the country will be affected differently, as previously suitable habitats lose their suitability and previously unoccupied habitats will become suitable. Particularly, southward and eastward shifts of climatically suitable habitats into Dasht-e Kavir and into Dasht-e Lut, respectively, are expected. Both Dasht-e Lut (area of about $51,800 \mathrm{~km}^{2}$ ) and Dasht-e Kavir (about 77,60o km²) are deserts with currently unsuitable habitat for the Houbara due to very limited, almost non-existent, rainfall. Whether birds occupying different regions in Iran will be able to respond to these shifts remains unknown, indicating that these potential shifts in suitable habitats can be considered as potential threats to this species in Iran.

The suitable areas that our model identified, particularly in areas that are expected to remain suitable under climate change, are ideal choices for concentrating conservation efforts for habitat management and monitoring of wintering populations of the Houbara. Overgrazing and hunting, the two main threats to the Houbara in Iran, also need to be controlled more effectively in such areas to make them more effective in conservation of the wintering population and also prepare them to be potential release sites for individuals bred in captivity (Heydari et al. 2010) in order to rehabilitate the declining populations of Houbara (BirdLife International 2014). Further investigations into the distribution and characteristics of breeding habitats for the Houbara in Iran are necessary in order to investigate protected area effectiveness and to ensure that seasonal needs of this species (Heezik and Seddon 1999) are met in Iran.

\section{Supplementary Material}

To view supplementary material for this article, please visit https://doi.org/10.1017/ So959270916000381

\section{Acknowledgements}

We thank the following colleagues for providing distribution data on the Asian Houbara Bustard: Hossein Abbasian of Yazd provincial office; and Leila Jolaii of Fars provincial office.

\section{References}

Aghainajafi-Zadeh, S., Hemami, M. R. and Heydari, F. (2011) Brooding site by Asiatic Houbara (Chlamydotis macqueenii) in central steppe of Iran. World Acad. Sci. Eng. Technol. 53: 558-56o.

Aghainajafi-Zadeh, S., Hemami, M. R., Karami, M. and Dolman, P. (2010) Wintering habitat use by houbara bustard

(Chlamydotis macqueenii) in steppes of Harat, central Iran. J. Arid Environ. 74: 912-917.

Aghainajafizadeh, S., Hemami, M. R. and Heydari, F. (2012) Nest-site selection by the Asian Houbara Bustard, Chlamydotis macqueenii, in the steppe of Herat, Iran: (Aves: Otidae). Zool. Middle East 57: 11-18. 
Asadalla, N. B., Abido, M. S., Abahussain, A. and Shobrak, M. (2015) Assembly of optimum habitats for Asian Houbara Bustard (Chlamydotis macqueenii) in the Arabian Peninsula: The vegetation aspects. Internatn. J. Biodivers. 2015: 6.

Asuero, A., Sayago, A. and Gonzalez, A. (2006) The correlation coefficient: An overview. Crit. Rev. Anal. Chem. 36: 41-59.

Avalos, V.d. R. and Hernández, J. (2015) Projected distribution shifts and protected area coverage of range-restricted Andean birds under climate change. Glob. Ecol. Conserv. 4: 459-469.

Battin, J. (2004) When good animals love bad habitats: ecological traps and the conservation of animal populations. Conserv. Biol. 18: 1482-1491.

BirdLife International (2014) Review of the global conservation status of the Asian Houbara Bustard Chlamydotis macqueenii. Report to the Convention on Migratory Species Office - Abu Dhabi. Cambridge, UK: BirdLife International.

Carrascal, L. M., Cayuela, L., Palomino, D. and Seoane, J. (2012) What species-specific traits make a bird a better surrogate of native species richness? A test with insular avifauna. Biol. Conserv. 152: 204-211.

Carrascal, L. M., Palomino, D., Seoane, J. and Alonso, C. L. (2008) Habitat use and population density of the houbara bustard Chlamydotis undulata in Fuerteventura (Canary Islands). Afr. J. Ecol. 46: 291-302.

Cayuela, L., Golicher, D., Newton, A., Kolb, H., de Alburquerque, F., Arets, E., Alkemade, J. and Pérez, A. (2009) Species distribution modeling in the tropics: problems, potentialities, and the role of biological data for effective species conservation. Trop. Conserv. Sci. 2: 319-352.

Combreau, O. and Smith, T. R. (1997) Summer habitat selection by houbara bustards introduced in central Saudi Arabia. J. Arid Environ. 36: 149-160.

Combreau, O., Launay, F. and Lawrence, M. (2005) Progress, challenges, and perspectives in Houbara Bustard conservation in Asia. In G. Bota, M. Morales, S. Mañosa, and J. Camprodon, eds. Ecology and conservation of steppe-land birds. Barcelona, Spain: Lynx Edicions \& Centre Tecnologic Forestal de Catalunya.
Combreau, O., Riou, S., Judas, J., Lawrence, M. and Launay, F. (2011) Migratory pathways and connectivity in Asian houbara bustards: evidence from 15 years of satellite tracking. PLOS ONE 6: e20570.

de Juana, E. (2005) Steppe birds: A characterisation. Pp. $25-48$ in G. Bota, M. Morales, S. Mañosa, and J. Camprodon, eds. Ecology and conservation of steppe-land birds. Barcelona, Spain: Lynx Edicions \& Centre Tecnologic Forestal de Catalunya.

Elith, J. (2000) Quantitative methods for modeling species habitat: comparative performance and an application to Australian plants. Pp. 39-58 in S. Ferson and M. Burgman, eds. Quantitative methods for conservation biology. New York, USA: Springer.

Elith, J., Phillips, S. J., Hastie, T., Dudík, M., Chee, Y. E. and Yates, C. J. (2011) A statistical explanation of MaxEnt for ecologists. Divers. Distrib. 17: 43-57.

ESRI (2009) ArcGis 9.3. Redlands, CA: Environmental Systems Research Institute.

Franklin, J. (2009) Mapping species distributions: spatial inference and prediction. Cambridge, UK: Cambridge University Press.

Gao, X., Combreau, O., Qiao, J., Yang, W., Yao, J. and Xu, K. (2009) Distribution and migration of houbara bustard(Chlamydotis undulata) in China. J. Arid Land 1: 74-79.

Gastón, A. and García-Viñas, J. I. (2011) Modelling species distributions with penalised logistic regressions: A comparison with maximum entropy models. Ecol. Model. 222: 2037-2041.

Goriup, P. D. (1997) The world status of the Houbara Bustard Chlamydotis undulata. Bird Conserv. Int. 7: 373-398.

Gray, T. N. E., Chamnan, H., Borey, R., Collar, N. J. and Dolman, P. M. (2007) Habitat preferences of a globally threatened bustard provide support for community-based conservation in Cambodia. Biol. Conserv. 138: 341-350.

Heezik, Y. V. and Seddon, P. J. (1999) Seasonal changes in habitat use by Houbara Bustards Chlamydotis [undulata] macqueenii in northern Saudi Arabia. Ibis 141: 208-215.

Hernandez, P. A., Graham, C. H., Master, L. L. and Albert, D. L. (2006) The effect of sample size and species characteristics on performance of differenct species distribution modeling methods. Ecography 29: 773-785. 
Heydari, F., Hemami, M. R. and AghainajafiZadeh, S. (2010) Captive breeding of Asiatic Houbara Bustard (Chlamydotis macqueenii) in Iran: Preliminary data and experiences. Iran. J. Biol. 23: 197-206.

Hijmans, R., Cameron, S., Parra, J., Jones, P. and Jarvis, A. (2004) The WorldClim interpolated global terrestrial climate surfaces. Version 1.3.

Kaboli, M., Aliabadian, M., Tohidifar, M., Hashemi, A. and Roselaar, C. S. (2012) Atlas of birds of Iran. Tehran, Iran: Iran Department of Environment.

Kaboli, M., Guillaumet, A. and Prodon, R. (2006) Avifaunal gradients in two arid zones of central Iran in relation to vegetation, climate, and topography. J. Biogeogr. 33: 133-144.

Lane, S. J., Alonso, J. C. and Martín, C. A. (2001) Habitat preferences of great bustard Otistarda flocks in the arable steppes of central Spain: are potentially suitable areas unoccupied? J. Appl. Ecol. 38: 193-203.

Le Cuziat, J., Lacroix, F., Roche, P., Vidal, E., Médail, F., Orhant, N. and Beranger, P. (2005a) Landscape and human influences on the distribution of the endangered North African houbara bustard (Chlamydotis undulata undulata) in Eastern Morocco. Anim. Conserv. 8: 143-152.

Le Cuziat, J., Vidal, E., Roche, P. and Lacroix, F. (2005b) Human activities affect the potential distribution of the Houbara Bustard Chlamydotis undulata undulata. Ardeola 52: 21-30.

Liu, X., Guo, Z., Ke, Z., Wang, S. and Li, Y. (2011) Increasing potential risk of a global aquatic invader in Europe in contrast to other continents under future climate change. PLoS ONE 6: eI8429.

López-Jamar, J., Casas, F., Díaz, M. and Morales, M. B. 2011. Local differences in habitat selection by Great Bustards Otis tarda in changing agricultural landscapes: implications for farmland bird conservation. Bird Conserv. Internatn. 21: 328-341.

Mansouri, J. (2006) Status of Houbara Bustard Chlamydotis undulata in five important habitats in Iran. Podoces 1: 17-20.

Mansoori, J. and Kiabi, B. (2003) Ecological status of the Houbara Bustard population in Iran. J. Environ. Stud. 31: 1-24.
Mian, A. (2003) On biology of Houbara Bustard (Chlamydotis undulata macqueenii) in Balochistan, Pakistan: Phytosociological analysis of habitat. Pak. J. Biol. Sci. 6: 1282-1295.

Moura, A. E., Sillero, N. and Rodrigues, A. (2012) Common dolphin (Delphinus delphis) habitat preferences using data from two platforms of opportunity. Acta Oecol. 38: 24-32.

Osborne, P., Alonso, J. and Bryant, R. (2001) Modelling landscape-scale habitat use using GIS and remote sensing: a case study with great bustards. J. Appl. Ecol. 38: 458-471.

Osborne, P. E. and Seddon, P. J. (2012) Selecting suitable habitats for reintroductions: Variation, change and the role of species distribution modelling. Pp. 73-104 in J. G. Ewen, D. P. Armstrong, K. A. Parker and P. J. Seddon. Reintroduction Biology. Chichester, UK: John Wiley \& Sons, Ltd.

Phillips, S. J. and Dudík, M. (2008) Modeling of species distributions with Maxent: new extensions and a comprehensive evaluation. Ecography 31: 161-175.

Phillips, S. J., Anderson, R. P. and Schapire, R. E. (2006) Maximum entropy modeling of species geographic distributions. Ecol. Model. 190: 231-259.

Riou, S., Judas, J., Lawrence, M., Pole, S. and Combreau, O. (2011) A 10-year assessment of Asian Houbara bustard populations: trends in Kazakhstan reveal important regional differences. Bird Conserv. Internatn. 21: 134-141.

Scott, D. A., Hamadani, H. M. and Mirhosseyni, A. A. (1975) The birds of Iran. Tegran, Iran: Department of the Environment.

Şekercioğlu, Ç. H., Primack, R. B. and Wormworth, J. (2012) The effects of climate change on tropical birds. Biol. Conserv. 148 : 1-18.

Seoane, J., Bustamante, J. and Diaz-Delgado, R. (2004) Competing roles for landscape, vegetation, topography and climate in predictive models of bird distribution. Ecol. Model. 171: 209-222.

Solomon, I. S., Qin, D., Manning, M., Chen, Z., Marquis, M., Averyt, K. B., Tignor, M. and Miller, H. L. (2007) Climate Change: The physical science basis. Contribution of Working Group I to the Fourth Assessment Report of the Intergovernmental Panel on 
Climate Change (pp. 1e18). Cambridge, UK: Cambridge University Press.

Suárez-Seoane, S., García de la Morena, E. L., Morales Prieto, M. B., Osborne, P. E. and de Juana, E. (2008) Maximum entropy niche-based modelling of seasonal changes in little bustard (Tetrax tetrax) distribution. Ecol. Model. 219: 17-29.

Swets, J. (1988) Measuring the accuracy of diagnostic systems. Science 240: 1285-1293.

Tourenq, C., Combreau, O., Lawrence, M., Pole, S. B., Spalton, A., Xinji, G., Al Baidani, M. and Launay, F. (2005) Alarming houbara bustard population trends in Asia. Biol. Conserv. 121: 1-8.

Velásquez-Tibatá, J., Salaman, P. and Graham, C. H. (2012) Effects of climate change on species distribution, community structure, and conservation of birds in protected areas in Colombia. Reg. Environ. Chang. 1-14.

Warren, D. L., Glor, R. E. and Turelli, M. (2010) ENMTools: a toolbox for comparative studies of environmental niche models. Ecography 33: 607-611.

Wolff, A. (2005) Influence of landscape and habitat heterogeneity on the distribution of steppe-land birds in the Crau, southern France. Pp. 141-168 in G. Bota, M. Morales, S. Mañosa and J. Camprodon, eds. Ecology and conservation of steppe-land birds. Barcelona, Spain: Lynx Edicions \& Centre Tecnologic Forestal de Catalunya.

Yang, W.-K., Qiao, J.-F., Combreau, O., Gao, X.-Y. and Zhong, W.-Q. (2003) Breeding habitat selection by the houbara bustard Chlamydotis [undulata] macqueenii in Mori, Xinjiang, China. Zool. Stud. 42: $470-475$.

Young, N., Carter, L. and Evangelista, P. (2011) A MaxEnt model v3.3.3 e tutorial (ArcGIS v1o). Denver, Colorado: Natural Resource Ecology Laboratory, Colorado State University and the National Institute of Invasive Species Science.

\section{MASOUD YOUSEFI ${ }^{1}$, MOHSEN AHMADI ${ }^{1,2}{ }^{2}$, ELHAM NOURANI ${ }^{1,3}$, ALI REZAEI $^{1}$, ANOOSHE KAFASH ${ }^{1}$, MOHAMMAD KABOLI ${ }^{1 *}$ \\ ${ }^{1}$ Department of Environmental Sciences, Faculty of Natural Resources, University of Tehran, Tehran, Iran. \\ ${ }^{2}$ Department of Natural Resources, Isfahan University of Technology, Isfahan, Iran. \\ 3 Graduate School of Fisheries Science and Environmental Studies, Nagasaki University, Nagasaki, Japan.}

\section{ALI KHANI}

Khorasan-e Razavi Provincial Office of the Department of the Environment, Mashhad, Iran.

\section{MOHAMMAD EBRAHIM SEHHATISABET}

Kerman Provincial Office of the Department of the Environment, Kerman, Iran.

MOHAMAD ALI ADIBI

Semnan Provincial Office of the Department of the Environment, Semnan, Iran.

\section{FAHIMEH GOUDARZI}

Hormozgan Office of the Department of the Environment, Hormozgan, Iran.

*Author for correspondence; e-mail: mkaboli@ut.ac.ir 